\title{
A epistemologia de John Dewey e o letramento informacional
}

\author{
The John Dewey's epistemology and informational literacy
}

Kelley Cristine Gonçalves Dias GASQUE'

Marcus Vinícius da CUNHA²

\section{RES U M O}

Este artigo discute o conceito de 'pensamento reflexivo' a partir da contextualização do legado intelectual de John Dewey. A reflexão se insere como elemento fundamental para a construção das competências necessárias à busca e ao uso da informação e, consequentemente, para o desenvolvimento pessoal e coletivo. Como o hábito de pensar reflexivamente no processo de letramento informacional é uma forma de aprender, igualmente algumas questões do ensino-aprendizagem são debatidas. A discussão sustenta-se na suposição de que o pensamento reflexivo é uma estratégia cognitiva que possibilita a compreensão mais profunda das questões, fenômenos e processos por meio da percepção das relações, da identificação dos elementos envolvidos, da análise e interpretação dos sentidos e significados, potencializando o processo de letramento informacional.

Palavras-chave: Aprendizagem. Busca e uso da informação. Dewey, John. Letramento informacional. Reflexão.

\section{A B S T R A C T}

The 'reflexive thinking' concept is discussed in this article as a means of contextualizing John Dewey's intellectual legacy. 'Reflection' represents a fundamental element for the construction of the necessary competences to information seeking and use, and consequently to individual and collective development. Since the reflexive thinking habit in information literacy is a way of learning, some questions concerning teaching and learning processes are also investigated. The discussion is, therefore, supported by the supposition that reflexive thinking is a cognitive strategy that allows a deeper comprehension of related problems, phenomena, and processes by means of the perception of the relations and the identification of involved elements, as well as the analysis and interpretation of meanings, empowering the information literacy process.

Keywords: Learning. Information seeking and use. Dewey, John. Information literacy. Reflection.

\section{NTRODUÇÃ O}

A informação constitui o principal insumo para o desenvolvimento pessoal e coletivo na sociedade contemporânea, denominada "sociedade da aprendizagem". A educação é o processo que deve preparar os indivíduos para lidarem com o aumento exponencial da informação, transformando-a em conhecimento necessário a uma vida digna. Cerca de uma década atrás, o relatório para a Organização das

\footnotetext{
1 Professora Doutora, Universidade Federal de Goiás, Faculdade de Comunicação e Biblioteconomia. Campus Samambaia, 74001-970, Goiânia, GO, Brasil. Correspondência para/Correspondence to: K.C.G.D. GASQUE. E-mail: <kelleycristinegasque@hotmail.com>.

2 Professor Doutor, Universidade de São Paulo. Ribeirão Preto, SP, Brasil. Recebido em 1/11/2009 e aceito para publicação em 23/7/2010.
} 
Nações Unidas para a Educação, a Ciência e a Cultura (UNESCO) da Comissão Internacional sobre Educação para o século XXI, sob o título "Educação - um tesouro a descobrir", mais conhecido como Relatório Jacques Delors (Delors et al., 1998, p.89), preconizou que compete à educação "fornecer, de algum modo, os mapas de um mundo complexo e constantemente agitado e, ao mesmo tempo, a bússola que permita navegar através dele", pois não é mais possível que as pessoas soçobrem nas ondas de informação que invadem os espaços públicos e privados.

Contudo, apesar dos reconhecidos esforços empreendidos atualmente, o acesso ao conhecimento tem sido dificultado por políticas informacionais ineficazes, investimentos precários nas empresas de bases tecnológicas, infraestrutura de informação pouco consolidada, designers diferenciados dos sistemas de informação, altos custos e insuficiência de programas sistematizados de formação humana e profissional, para mencionar os mais evidentes. Outro fator extremamente significativo para o acesso "às múltiplas formas culturais da representação simbólica", crucial para a emancipação humana, de acordo com Pozo (2005, p. 11 ), é o que diz respeito à valorização do processo de aquisição do conhecimento, ferramenta poderosa para democratizar o saber.

A produção de conhecimento ocorre mediante - desenvolvimento de capacidades específicas para realizar as atividades de busca e de uso da informação. Partindo do pressuposto que essas atividades são complexas e requerem processos específicos de aprendizagem, o pensamento reflexivo, tal qual proposto por John Dewey, talvez seja "a ferramenta mais útil que uma pessoa possa possuir [...] pois exige uma participação mais ativa em relação ao pensamento convencional, mais imaginação e criatividade" e, como consequência, oferece um número maior de insights com poder de generalização e maior habilidade para desenvolver e solucionar problemas (Bigge, 1977, p.324).

Propõe-se, neste artigo, o emprego do pensamento reflexivo como elemento fundamental na construção das competências necessárias à busca e ao uso da informação e, consequentemente, para o desenvolvimento pessoal e coletivo. As questões de ensinoaprendizagem são abordadas por estarem estreitamente vinculadas ao hábito de pensar reflexivamente, em especial, no letramento informa-cional. Este, por sua vez, refere-se a desenvolvimento da capacidade de buscar e usar a informação com competência. $O$ conceito origina-se do termo "information literacy" e designa o estado ou condição daquele que é "literate". Abrange a codificação e decodificação dos signos e símbolos e o uso competente e frequente das habilidades de interpretação da realidade.

A discussão sustenta-se na suposição de que o pensamento reflexivo é uma estratégia cognitiva que possibilita a compreensão mais profunda de fenômenos e processos por meio da percepção das relações, da identificação dos elementos envolvidos, da análise e interpretação dos sentidos e significados, potencializando o processo de aprendizagem e tornando mais eficazes as atividades de busca e uso da informação.

\section{O PENSAMENTO REFLEXIVO NA PERSPECTIVA DEWEYANA}

Teixeira (1955) intitula Dewey de filósofo da conciliação (ou reconciliação) e ajustamento (ou reajustamento) entre a tradição e o conhecimento científico, o passado e presente. Argumenta que a filosofia deweyana se apoia em uma realidade em transformação, cuja lógica possui bases naturalísticas - biológicas e culturais -, em que os seres vivos agem e reagem em seu meio, alterando a si mesmos e ao universo. Nesse contexto, o homem constitui-se em um dos elementos de modificação do universo, por meio da experiência e com a utilização da linguagem. Portanto, o comportamento humano se insere em um ambiente em que o físico e o orgânico se fazem social e cultural por aprendizagem, aquisição e herança social, considerando-se os símbolos, sinais e sentidos a serem compreendidos e compartilhados com os outros indivíduos.

A filosofia deweyana compreende a pessoa livre para escolher as ações e tomar decisões em um processo social, democrático, de supostas oportunidades iguais para todos. Segundo Cunha (2001), essa concepção política expressa uma crítica à ordem social vigente, em particular à desigualdade entre as classes sociais no capitalismo. A visão democrática de Dewey sugere o não conformismo à realidade presente, mas um programa de lutas destinado a ocasionar transformações. Nesse programa, a principal arma é o pensamento reflexivo, cujo modelo é a atividade 
científica, aplicado à vida cotidiana e à educação escolar ${ }^{3}$.

A noção de pensamento reflexivo é desenvolvida por Dewey (1979) na obra Como pensamos, de 1910, reescrita posteriormente em 1933. Segundo o autor, o pensamento reflexivo não pode ser confundido com o curso desordenado de ideias ociosas e caóticas que passam pela mente humana. Tampouco pode ser entendido como criação ov elaborações imaginárias que mesmo tendo coerência interna ou forma lógica, em alguns casos apenas se assemelham ao pensamento reflexivo. O pensar reflexivo é aquele que é suscitado por um problema ou situação obscura que requer esclarecimento. Não se confunde com busca da "verdade", pois todas as suas conclusões são, para Dewey, provisórias, sujeitas a serem testadas e, se preciso, reformuladas.

O pensamento reflexivo refere-se à melhor forma de pensar com vistas à solução de um problema. É um tipo de pensamento que consiste em examinar mentalmente um assunto e direcionar-lhe o fluxo em partes sucessivas, em que cada ideia se apóia nas antecessoras e produz as seguintes. $O$ resultado decorre de um movimento teleológico por meio de um esforço consciente e voluntário.

O pensamento reflexivo abrange duas fases bem definidas: "1) um estado de dúvida, hesitação, perplexidade mental, o qual origina o ato de pensar; e 2) um ato de pesquisa, procura, inquirição, para encontrar material que resolva a dúvida, ausente e esclareça a perplexidade" (Dewey, 1979, p.22). Portanto, o pensar reflexivo é orientado para a solução de uma dúvida ou problema, em que a natureza do problema determinará os objetivos que orientarão o processo de pensar. Os dados para a solução do problema podem ser oriundos de buscas de informações e das próprias experiências passadas. A característica principal do pensamento reflexivo é a ação, isto é, a disposição para a investigação.

$\mathrm{Na}$ proposição deweyana, algumas atitudes contribuem para o desenvolvimento do pensamento reflexivo: 1) espírito aberto, cuja essência está na curiosidade e na busca do novo, assim como, na independência de preconceitos, de partidarismo; 2) envolvimento "de todo coração", envolvimento interessado e entusiasmo genuíno com algo; e 3) responsabilidade, que significa analisar e enfrentar as consequências do passo projetado, vislumbrar o futuro, levar o trabalho até o fim e questionar sobre a significação do que se aprende, discernindo a diferença proporcionada pelo novo conhecimento às outras crenças e ações.

Além das atitudes, existem tendências e forças inatas - como curiosidade, sugestão e ordem - que agem em todos os indivíduos normais e podem ser empregadas no exercício do pensamento reflexivo. A curiosidade é o desejo intenso de sentir, ver, ouvir, falar, experimentar algo novo ou desconhecido, revelando uma contínua atividade de investigação. Assume um caráter intelectual quando se converte em sequência de investigações interligadas, dirigindo-se para um fim, possibilitando a ampliação da experiência. Das experiências, surgem espontaneamente as sugestões, ideias mais primitivas que por meio da ordem - propriedade de controlar as sucessões em sequências ordenadas rumo a uma conclusão - podem se converter em pensamento reflexivo.

Dewey (1979) considera as diferenças entre o raciocínio formal e o pensamento. A matéria da lógica formal é impessoal e independe da atitude, do desejo ou da intenção de quem pensa, não possuindo vínculos com o contexto, em oposição ao pensamento que depende dos hábitos e atitudes de cada pessoa. $\bigcirc$ pensamento pode ser entendido como processo psicológico e como forma lógica ou produto. Um exemplo é a analogia entre as expedições e viagens de exploração (processo) e o mapa (produto). O produto pode ser usado sem referenciar as tentativas, obstáculos e dúvidas pelas quais passaram os exploradores, sendo empregado para expor os resultados do pensamento, ao contrário do processo. O pensar real tem sua própria lógica que se refere ao movimento contínuo e ordenado em direção à conclusão. Sendo assim, o psicológico e o lógico não se opõem mutuamente, mas são conexos, como estágio inicial e estágio terminal do mesmo processo, cujas interações devem ser propiciadas pela educação.

A constituição de juízos, parte essencial do processo reflexivo, refere-se à decisão sobre a fundamentação dos fatos envolvidos na resolução do problema. As duas funções do juízo são a análise,

${ }^{3}$ Cunha (2001) esclarece que Dewey, ao expressar suas concepções políticas, opõe-se, ao mesmo tempo, ao liberalismo laissez-faire e ao marxismo de sua época. 
atividade de pôr em relevo um fato ou qualidade como significativo, e a síntese, que consiste em apreender a ligação dos fatos com a conclusão, isto é, a localização do fato dentro de um contexto. Essas funções são interativas, pois "a análise conduz à síntese e a síntese completa a análise" (Dewey, 1979, p.134).

As ideias, instrumentos de interpretação que subsidiam o juízo, são definidas pela função e uso. A aquisição dos significados se produz pela atividade do sujeito ante os objetos, ou seja, quando se faz algo especial em relação a cada um dos elementos envolvidos no problema. O sentido de cadeira, por exemplo, não se resume a uma representação mental do objeto, mas diz respeito à compreensão dos vínculos entre o significado e sua função. Sobre esse tema, Dewey (1979, p. 140) argumenta que:

Apreender a significação de uma coisa, de um acontecimento ou de uma situação é ver a coisa, acontecimento ou situação, em suas relações com outras coisas: notar como opera ou funciona, que conseqüências traz, qual a sua causa e possíveis aplicações.

Outro aspecto importante da significação vincula-se às concepções, significados estabelecidos e reconhecidos como certos e garantidos, que "nos habilitam a generalizar, a estender e a levar a nossa compreensão de uma coisa a outra" (Dewey, 1979, p. 152). As concepções são desenvolvidas pela experiência. Uma criança, por exemplo, ao conhecer um cachorro, não o percebe originalmente com todas as características. Pelo contrário, ele se apresenta como uma vaga ideia, até que outros animais vão sendo conhecidos, como porcos e cavalos, delimitando gradualmente as propriedades definidas do conceito de cachorro. Assim, uma significação é clara quando permite distinguir entre o que se aplica a um e a outro grupo de coisas, tornando os conceitos gerais pelo uso.

Em resumo, a epistemologia deweyana tem em seu cerne o pensamento reflexivo, que corresponde ao processo de investigação com vistas à produção do conhecimento, identificando-se com o método científico. A reflexão deve levar em conta a realidade cotidiana impregnada de crenças e expectativas, assim como os critérios de julgamento e a realidade social e política (Nóvoa, 1992, p. 103). Consiste, pois, em uma "teoria da vida intelectual, isto é, uma teoria do pensamento, da experiência reflexiva" (Teixeira, 1955, p.3), em que as formas lógicas são elaboradas pelo questionamento permanente do homem em busca de respostas às suas indagações existenciais. A história do pensamento humano vincula-se às atividades de buscas e de resolução de problemas. $\bigcirc$ que se obtém, por fim, é o conhecimento, visto por Dewey como "assertividade garantida" (warranted assertibility), expressão que traduz a ideia de provisoriedade daquilo que constitui o resultado do processo de investigar.

\section{O LETRAMENTO INFORMACIONAL}

Buscar e usar a informação parecem ser atividades naturais do ser humano. Desde os primórdios, o homem, diante de conflitos ou desequilíbrios de qualquer natureza, utiliza a informação para resolver problemas e, consequentemente, adaptar-se e integrarse ao ambiente. Contudo, nem sempre as pessoas possuem conhecimento sistematizado e competências para realizar essas atividades, agindo de forma quase sempre intuitiva e sem consciência do processo como um todo integrado.

A expansão da consciência e a autoconsciência permitem a transposição do hiato que separa o senso comum do domínio de um arcabouço conceitual consistente e articulado (Churchland, 2004). A reflexão amplia a consciência do processo de busca e uso da informação, possibilitando a percepção dos elementos envolvidos e as relações entre eles. As várias atividades e procedimentos que integram o referido processo se constituem em conteúdos de aprendizagem, que permitem o desenvolvimento da consciência e a obtenção de resultados mais eficazes. Assim sendo, a elaboração do plano de busca de informação; a identificação das habilidades necessárias para lidar com a informação; a capacidade de lidar com as tecnologias de informação e comunicação; a identificação de novas estratégias perante as barreiras que dificultam o acesso à informação; a compreensão crítica da produção da informação científica e tecnológica; a análise ideológica das informações disseminadas na sociedade; o desenvolvimento de valores e da dimensão ética no ciclo informacional, dentre outros, são conteúdos que devem fazer parte do currículo educacional. Eles precisam ser apropriados pelos indivíduos, preferencialmente por meio do pensamento reflexivo, para a produção de conhecimentos em prol de si mesmos e 
da construção de uma sociedade mais igualitária, justa e sustentável.

Reconhece-se que talvez não sejam imprescindíveis muitos conhecimentos para responder a questionamentos simples e pontuais. No entanto, para a resolução de problemas mais complexos, faz-se necessária uma formação específica. Principalmente, em áreas do conhecimento pouco familiares às pessoas, a tendência é a intensificação das dificuldades para lidar com a informação. Nesses casos, podem-se identificar resultados insatisfatórios, repetição de erros ou respostas inexplicáveis, descobertas de materiais pouco relevantes, pouco conhecimento para lidar com a tecnologia, especialmente com as técnicas de busca e a funcionalidade dos sistemas de informação (Hepworth, 20..?). Tais problemas repercutem diretamente no conhecimento produzido, pois indivíduos mais capacitados para buscar informação obtêm informação de qualidade e com pontos de vistas diversificados, o que possibilita melhores resultados na aprendizagem (Limberg, 1999).

Essas pesquisas, dentre outras, demonstram a relevância da aquisição e aplicação de conteúdos que compõem o letramento informacional, correspondendo à estruturação sistêmica de um conjunto de competências que possibilita integrar as ações de localizar, selecionar, acessar, organizar e gerar conhecimento. Tais competências possibilitam a tomada de decisão, resolução de problemas e produção de pesquisas. $\bigcirc$ indivíduo letrado informacionalmente será capaz de determinar a extensão das informações necessárias, acessá-las efetiva e eficientemente, avaliar criticamente a informação e as suas fontes, relacionar a informação selecionada com os conhecimentos prévios, usá-la efetivamente para acompanhar um objetivo específico, compreender os aspectos econômicos, legais e sociais do contexto do uso da informação e acessá-la e usá-la ética e legalmente (Association of College and Research Library, 2000, p.8).

Ressalta-se que o letramento informacional é um processo de aprendizagem, que deve ocorrer como ação contínua ao longo da vida. A aprendizagem relaciona-se à aquisição do conhecimento, inerente ao ser humano, que perpassa as várias atividades do comportamento informacional. É o aprender a pensar, que abrange conceitos, procedimentos, atitudes e valores, consistindo em mudanças cognitivas relativamente permanentes, resultantes das inter-relações entre a nova informação, a reflexão e a experiência prévia.
Assim sendo, os conhecimentos necessários para buscar e usar informação de forma eficiente e eficaz são conteúdos que devem ser ensinados, aprendidos, aplicados e avaliados. Tal processo implica a discussão do papel da escola e do professor, da necessidade da ampliação da linguagem, da importância da gradação dos referidos conteúdos, do trabalho com projetos e de se considerar a experiência prévia do aprendiz. Para tanto, no próximo tópico, busca-se oferecer subsídios para que o ensino-aprendizagem desses conteúdos seja tratado de forma a torná-los mais significativos para os aprendizes, para que possam aplicá-los em sua vida pessoal e profissional.

\section{CONTRIBUIÇÕES DE DEWEY PARA O ENSINO E A APRENDIZAGEM DO LETRAMENTO INFORMACIONAL}

Para Dewey (1979), a escola é uma instituição necessária à construção de cidadãos dignos, responsáveis e reflexivos que deveriam posicionar-se ativamente em prol do desenvolvimento coletivo. Porém, critica fortemente as escolas tradicionais que somente se preocupam com o ensino e não com a aprendizagem dos estudantes. A escola, e aqui se incluem as universidades, deve propiciar a formação de hábitos reflexivos, estabelecendo condições que despertem a curiosidade; preparação das conexões que geram o fluxo de sugestões para uma problematização, levando-se em conta as experiências dos estudantes e o favorecimento da consecutividade na sucessão das ideias para resolução dos problemas.

A educação baseia-se "na formação de hábitos de pensar despertos, cuidadosos, meticulosos" (Dewey, 1979, p.86). Esses hábitos transcendem a acumulação e a retenção de informações, constituindo-se em conhecimento quando o assunto é compreendido, isto é, quando as várias partes das informações são apreendidas em suas relações mútuas. Assim, os métodos que enfatizam a memorização não compreensiva dos conteúdos pelo uso de expedientes mecânicos tornam a pedagogia desacreditada.

À educação, cabe, pois, propiciar ambiente para a emergência da disciplina e da liberdade. A disciplina refere-se ao controle, à avaliação e à verificação dos meios necessários para atingir os fins. Por sua vez, a liberdade é a ação do sujeito na interação com o mundo, sem a necessidade de tutela exterior, podendo 
ser conquistada pela superação dos obstáculos, pelo uso do pensamento para o domínio dos impulsos, moderação dos apetites e controles circunstanciais. Nesses termos, Dewey (1979, p.96) assegura que "a verdadeira liberdade é intelectual".

pensar reflexivo constitui-se de uma série de atividades físicas e mentais para descobrir o novo ou compreender o conhecido por outro prisma. A ideia de pensamento vincula-se com a indagação permanente que transcende a busca por respostas prontas, que apenas estimula a memorização não compreensiva. Por isso, o desenvolvimento da arte de perguntar para levar o estudante a não reproduzir as respostas, mas a adotar uma conduta nova perante o novo problema deve ser uma preocupação constante do professor. As perguntas devem fazer com que os estudantes se centrem na matéria e não na resposta certa em que o professor pensou. Devem, também, vir em um continuum assegurando o desenvolvimento dos conteúdos e os religando aos outros conhecimentos. $E$, por fim, devem propiciar a revisão dos conhecimentos anteriores e despertar o espírito do aluno para seguir avante.

Dewey (1979) enfatiza a importância da aquisição da linguagem como fator de adaptação social que permite compreender os significados e sentidos do mundo. A linguagem não é, portanto, sinônimo de pensamento, mas instrumento necessário a ele e à comunicação. Aprender constitui-se, pois, na apreensão da significação e relação das coisas, lembrando-se que o símbolo se reveste de significado apenas mediante a experiência. A função primordial da linguagem é atuar pela manifestação do desejo, da emoção e do pensamento nas relações com as pessoas e favorecer as relações mais íntimas, para somente depois ser empregada como veículo consciente do pensamento em um processo gradual. Durante esse processo, cabe à educação orientar o desenvolvimento da linguagem como instrumento intelectual favorecendo o enriquecimento do vocabulário, a exatidão e precisão das palavras e aquisição do hábito de falar de modo coerente.

Os conteúdos informacionais precisam ser ensinados gradualmente desde a educação básica, principalmente com a utilização de brincadeiras e jogos, como recursos pedagógicos. Isso porque são instrumentos cruciais para a construção da significação e das suas relações, o que possibilita a aquisição das capacidades representativas. As crianças devem se apropriar dos conceitos, aprofundando seus conhecimentos de forma crescente. À medida que vão se desenvolvendo, a livre fantasia cede espaço às atividades mentais que materializem adequadamente a significação das coisas e dos processos. De modo gradativo, deve-se possibilitar aos aprendizes a resolução dos problemas por meio da reflexão, experimentação pessoal e aquisição de conteúdos definidos que permitam o desenvolvimento das noções científicas mais especializadas.

Dewey (1979) propõe o trabalho com projetos como instrumento organizador curricular. $\bigcirc$ valor do projeto está sujeito a certas condições, como o interesse, o valor intrínseco que transcende o prazer imediato e tem valor por si mesmo; para isso, é preciso haver a apresentação de problemas que despertem a curiosidade e exijam a busca de informação. A condição final é que os projetos se prolonguem por um intervalo de tempo, permitindo que os planos e objetivos sejam atingidos eficientemente.

$\bigcirc$ processo de ensino-aprendizagem realizado por meio de projetos favorece o pensamento reflexivo. $\mathrm{O}$ aprendiz começa a investigar a partir de um problema, que pode ser sobre uma inquietação ou uma posição a respeito do mundo. A partir daí, ele se engaja em situações de busca e de uso da informação. Contudo, essas situações não podem ocorrer de maneira descontextualizada, sem conexão com o que se aprende, pois se corre o risco da não apreensão do significado de cada ação. Quando bem conduzido, o resultado é a construção de uma situação de aprendizagem em que os próprios estudantes começam a participar do processo de criação, buscando respostas às suas dúvidas. Essa forma de trabalho permite vincular os conteúdos a serem apreendidos com os conteúdos e procedimentos de busca e de uso da informação.

No processo de aprendizagem, os aprendizes devem empregar o pensamento reflexivo a partir de suas experiências, isto é, partindo do concreto em direção ao abstrato. $\bigcirc$ conceito concreto exprime diretamente a significação e o uso para o indivíduo, não requerendo esforço algum para ser apreendido. Por outro lado, a abstração designa termos e conceitos não familiares, necessitando que se evoquem inicialmente as coisas familiares, para em seguida procurar as relações entre elas e o que não é compreensível. Nesse caso, o abstrato refere-se à aquisição do sentido por meio da inferência. Tradicionalmente, a escola tem 
transmitido informação, sem levar em conta o processo de descoberta dos aprendizes. Dewey (1979) destaca a oposição imensa que ocorre entre o recitar e o refletir, pois a passividade dos aprendizes, como aqueles que assimilam e retêm a informação apresentada, não favorece o crescimento intelectual.

Assim, nos programas de formação de competências informacionais, o favorecimento da compreensão e das possibilidades transformadoras da experiência pelos estudantes tornam-se aspectos importantes. A experiência deve ser problemática e crítica, reconhecendo as implicações políticas e morais dela própria. Questões como: "por que estamos fazendo o que estamos fazendo?", "por que este conhecimento está sendo aprendido?" (Giroux, 1997, p.81) possibilitam a ampliação cognitiva. Ou seja, os estudantes devem compreender o relacionamento entre a teoria e os fatos "principalmente porque a teoria representa a estrutura conceitual que medeia os seres humanos e a natureza objetiva da realidade social mais ampla" (Giroux, 1997, p.82).

Na visão de ensino em que a reflexão se situa como instrumento central da educação, favorecendo a participação dos aprendizes de maneira ativa em busca de respostas para os questionamentos, o papel do professor é o de atuar como líder intelectual conhecedor das necessidades e possibilidades do grupo. Ele precisa de entusiasmo e conhecimento amplo quanto à matéria que ensina para contagiar o aprendiz. Além disso, precisa ter conhecimentos técnicos, entendidos por Dewey (1979) como o conhecimento profissional que inclui, por exemplo, conhecimentos de psicologia, história da educação e métodos adequados a cada disciplina.

- professor deve preparar cada lição considerando os objetivos de aprendizagem, mas sem deixar de tirar proveitos de incidentes e perguntas inesperadas. Para tanto, deve formular a si mesmo questionamentos sobre os conhecimentos prévios e estudos anteriores que os aprendizes possuem sobre o assunto, auxiliá-los a fazer as conexões, mostrar as necessidades que os levarão para a direção desejada e as estratégias mais apropriadas para esclarecer o assunto.

\section{REFERÊNCIAS}

ASSOCIATION OF COLLEGE AND RESEARCH LIBRARY (EUA). Information literacy competency for higher education. Chicago:
Coroando esta discussão, é necessário pensar no letramento informacional como um programa transversal aos conteúdos de sala de aula. $\bigcirc$ letramento informacional deve, então, ser responsabilidade compartilhada pelos educadores da escola - professores, coordenadores, assessores, orientadores e bibliotecários - em um esforço de mediação formativa a ser sistematizado no Projeto Político Pedagógico e operacionalizado na matriz curricular das escolas de Educação Básica e das universidades, integrando os conteúdos de busca e de uso da informação aos conteúdos disciplinares.

\section{CONSIDERAÇÕES FINAIS}

O letramento informacional é um processo de aprendizagem que, quando realizado de forma consciente, reflexiva e contextualizada, favorece a produção do conhecimento, em especial do científico. Tal processo pode ser desenvolvido, em termos de ensino-aprendizagem, por diferentes propostas. Neste trabalho, argumentou-se a favor do pensamento reflexivo, tal qual proposto por John Dewey, como instrumento indispensável para ampliar a visão desses processos, como parte inerente do próprio conhecimento, e, como tal, não pode ser dissociado do ato de conhecer. A importância do pensamento reflexivo na produção de conhecimento revela-se no questionamento dos conteúdos e explicitação de seus pressupostos e fundamentos, alimentando-se da disposição para o diálogo, incentivado pela dúvida e pelo espírito crítico.

O pensamento reflexivo permite transcender as fronteiras da razão instrumental para alimentar uma sabedoria que se consolida pela sensibilidade capaz de elaborar sua própria significação, dedicada à construção da reciprocidade e do respeito à alteridade e à diversidade. É essa sabedoria que propicia o fundamento ético que "definirá os encontros humanos como horizontes e transformará uma realidade que não existe sem a presença das pessoas, tanto quanto estas sem ela" (Tescarolo, 2004, p. 135). 
BIGGE, M.L. Teorias da aprendizagem para professores. São Paulo: EPU, 1977.

CHURCHLAND, P.M. Matéria e consciência: uma introdução contemporânea à filosofia da mente. São Paulo: UNESP, 2004.

CUNHA, M.V. John Dewey: a utopia democrática. Rio de Janeiro: DPA, 2001.

DELORS, J. et al. Educação: um tesouro a descobrir. São Paulo: Cortez, 1998. Disponível em: <http://unesdoc.unesco.org/ images/0012/001298/129801 por.pdf > . Acesso em: 3 jan. 2007.

DEWEY, J. Como pensamos: como se relaciona o pensamento reflexivo com o processo educativo, uma reexposição. 4. ed. São Paulo: Nacional, 1979.

GIROUX, H.A. Os professores como intelectuais. Porto Alegre: Artmed, 1997.

HEPWORTH, M. Information literacy from the perspective of learners: implications for teaching information literacy and skills.
Available from: <www.elit-conf.org/itilit2002/papers/ppt/ 08h 1.doc>. Cited: 20 Sept. 2007.

LIMBERG, L. Experiencing information seeking and learning: a study of the interaction between two phenomena. Information Research, v.5, n. 1, 1999. Available from: <http://informationr.net/ ir/5-1/paper68.html>. Cited: 23 Sept. 2006.

NÓVOA, A. Os professores e a sua formação. Lisboa: Dom Quixote, 1992.

POZO, J.I. Aquisição de conhecimento. Porto Alegre: Artmed, 2005.

TEIXEIRA, A. Bases da teoria lógica de Dewey. Revista Brasileira de Estudos Pedagógicos, v.23, n. 57, p.3-27, 1955.

TESCAROLO, R. A escola como sistema complexo: a ação, o poder e o sagrado. São Paulo: Escrituras, 2004. 